\title{
Normal faulting on Europa: implications for ice shell properties
}

\author{
F. Nimmo ${ }^{\mathrm{a}, *}$, P. Schenk ${ }^{\mathrm{b}}$

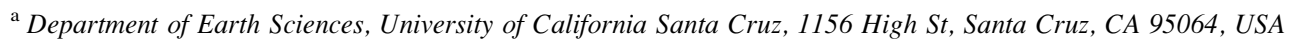 \\ ${ }^{\mathrm{b}}$ Lunar and Planetary Institute, 3600 Bay Area Blvd, Houston, TX 77058, USA
}

Received 27 August 2004; received in revised form 2 May 2005; accepted 26 August 2005

Available online 29 September 2005

\begin{abstract}
We identify two likely normal faults on Europa, of lengths $\approx 30$ and $11 \mathrm{~km}$. A simple flexural model of fault-related topography gives effective elastic thicknesses of 1.2 and $0.15 \mathrm{~km}$, respectively, and the resulting inferred fault strength is of order $1 \mathrm{MPa}$. The maximum fault displacement: length ratio for each fault is $\approx 0.02$, comparable with values on silicate planets. We combine this observation with a modified linear elastic fracture mechanics model to conclude that the shear modulus of the Europan surface must be significantly less than that for unfractured ice. The low value of the modulus is probably due to near-surface fracturing or porosity, which will affect the material's radar properties and seismic velocities. For a likely reduction in shear modulus of an order of magnitude, the driving stresses inferred are about 6-8 MPa, much higher than present-day diurnal tidal stresses. However, stresses approaching these values can be generated by non-synchronous rotation or polar wander, while stresses exceeding these values arise during ice shell freezing. If the entire larger fault breaks, it will generate an event of seismic magnitude $M_{\mathrm{s}} \approx 5.3$.
\end{abstract}

(c) 2005 Elsevier Ltd. All rights reserved.

Keywords: Extension; Ice; Tectonics; Galilean satellites; Displacement

\section{Introduction}

Europa's surface is pervasively fractured as a result of tidal deformation (Greenberg et al., 1998). A considerable amount of work has been done on both the fracture orientation (Kattenhorn, 2002; Greenberg et al., 2003; Spaun et al., 2003) and the direction and amount of motion (Hoppa et al., 2000; Prockter et al., 2002; Michalski and Greeley, 2002; Sarid et al. 2002; Schulson, 2002; Patterson et al., 2004). In the absence of altimetry data, photoclinometry (PC) or stereo techniques have been used to obtain icy satellite topography (e.g. Schenk and Moore, 1995; Giese et al., 1998; Schenk, 2002). The results have been used in studies of double ridges (Head et al., 1999; Hurford et al., 2004), chaos regions (Williams and Greeley, 1998; Figueredo et al., 2002; Schenk and Pappalardo, 2004) and bands (Prockter et al., 2002; Nimmo et al., 2003a).

In this paper, we use stereo-derived topography (Schenk, 2002) to identify two possible normal faults on Europa. Little

\footnotetext{
* Corresponding author. Tel.: +1 831459 1783; fax: +1 8314593074 .

E-mail address: fnimmo@es.ucsc.edu (F. Nimmo).
}

attention has hitherto been paid to the topography of normal faults on Europa, although normal fault topography and extension on the somewhat similar icy surface of Ganymede have been described by several authors (Collins et al., 1998; Prockter et al., 1998; Nimmo et al., 2002; Pappalardo and Collins, 2005). On Earth and Venus, normal fault observations have been used to infer various mechanical properties of the material in which they form (e.g. Jackson and White, 1989; Kusznir et al., 1991; Foster and Nimmo, 1996). Here, we apply some simple techniques from the terrestrial literature to probe the mechanical properties of the ice shell on Europa.

\section{Observations}

Fig. 1a shows a Galileo image of an area in the trailing hemisphere of Europa, between Argiope and Katrous Lineae (Figueredo and Greeley 2004, Fig. 1). The bulk of the image consists of ridged plains material. Two dominant structural trends are evident: an early ENE trend, which is overprinted by a more recent NW trend. The northern half of the image contains several areas of disrupted material, which form the 

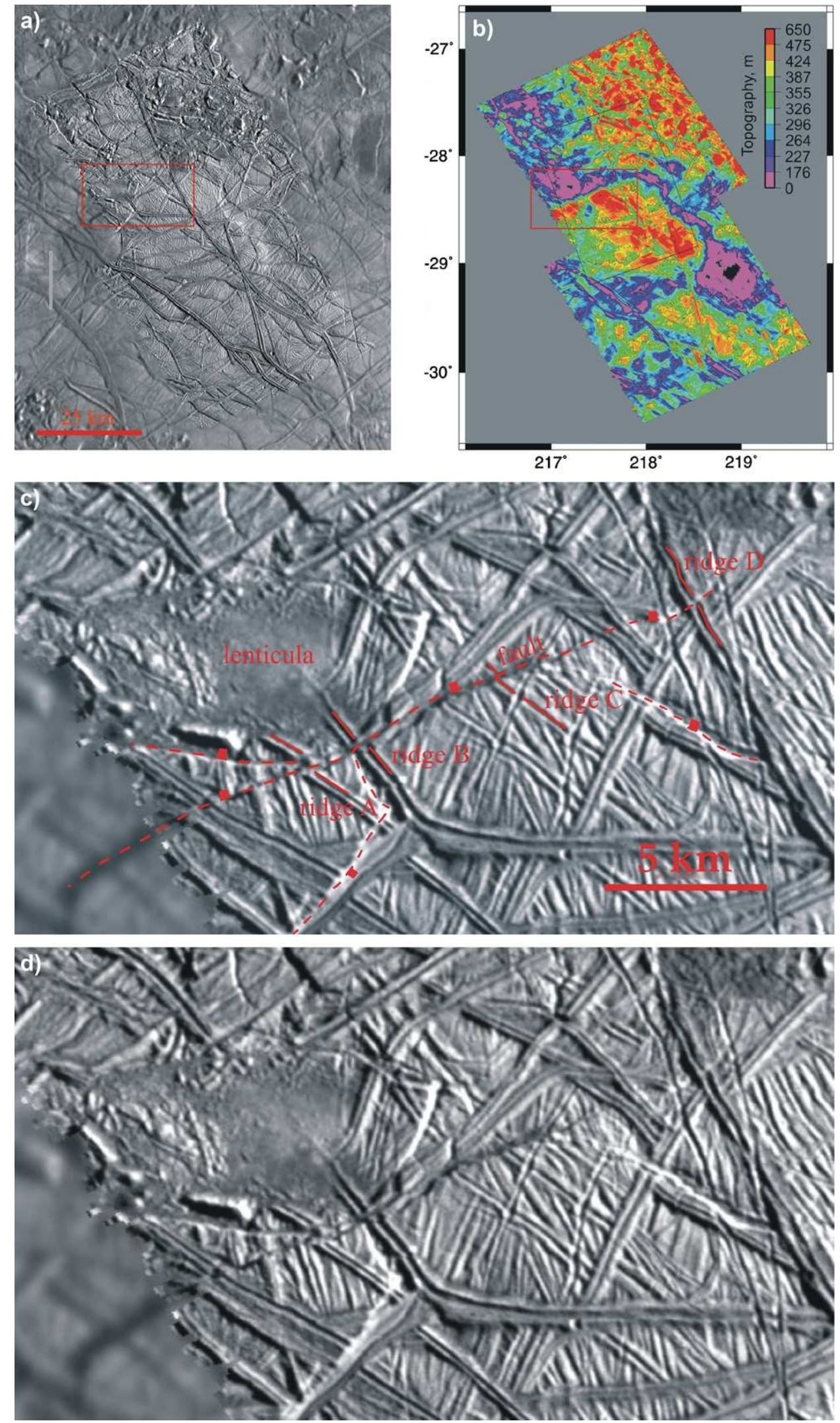

Fig. 1. (a) High-resolution images (PDS no. 466669339 and 466669352, $55 \mathrm{~m} /$ pixel) from Galileo observation sequence 17ESDISSTR01, superimposed on lower resolution regional image (PDS no. 466664278, $220 \mathrm{~m} /$ pixel). Red box denotes area magnified in (c). High resolution image has an incidence angle of $72^{\circ}$, emission angle $32^{\circ}$, camera look direction WNW and solar azimuth ENE; low resolution image parameters are $75,20^{\circ}, \mathrm{S}$ and ENE, respectively. (b) Topography of the area shown in (a), based on a combination of stereo and photoclinometry. Original resolution $55 \mathrm{~m} /$ pixel, vertical error $55 \mathrm{~m}$, contour interval $200 \mathrm{~m}$. Data gridded at $0.0025^{\circ}$ intervals; $1^{\circ}=27 \mathrm{~km}$ at the equator on Europa. Black box denotes area containing 30 fault-perpendicular profiles used in constructing Figs. 4 and 5 . (c) Magnified view of portion of (a), showing proposed normal fault traces and structural offsets. (d) As for (c), but without annotation. 
southern margins of a chaos area mapped by Figueredo and Greeley (2004).

Fig. $1 \mathrm{~b}$ shows the topography of the same area, derived by combining high resolution PC topography with lower resolution (but more reliable at long wavelengths) stereo-derived topography, using the technique described in Schenk (2002), Schenk and Pappalardo (2004) and Schenk et al. (2004). The DEM has an estimated absolute vertical precision of $55 \mathrm{~m}$ (and a few meters in relative precision) and a pixel resolution of $55 \mathrm{~m}$ (identical to the original image mosaic). Several of the NW-trending double ridges show up prominently in the topography, but the most obvious feature is a trench-like topographic low, which outlines a raised block in the center of the image. The northern edge of this block is sharply defined and highly linear. Fig. 1c shows a magnified view of this northern block margin. The margin is defined by a faint, dark lineation (dashed red line), which appears to have caused a slight offset in several ridges (A, B, C, D). The identification of structural offsets and an associated topographic step suggest that this linear feature is a normal fault. The topographic data suggest that this fault extends some distance $\mathrm{E}$ of the end of the mapped trace in Fig. 1c, and there do appear to be structural discontinuities that support this observation, for instance at ridge $\mathrm{D}$. The fault also appears to continue to the $\mathrm{W}$ of the high-resolution coverage, showing up as a distinct shadow in the lower resolution image. The downthrown area towards the $\mathrm{W}$ end of the high-resolution coverage contains a $4 \mathrm{~km}$ diameter dark circular feature (lenticula). This feature appears to have disrupted pre-existing ridges and is topographically low.

While clearly younger than ridged plains, the age of this fault is indeterminate due to the fact that it crosses only ridged plains. Dark material from the adjacent lenticula laps up almost to the fault scarp but does not actually contact it. The main fault trace is very linear over long spatial scales, but somewhat irregular over distances of $100 \mathrm{~m}$ or so (Fig. 1d). This irregularity may reflect control by original ridges or projection effects due to the moderately oblique viewing geometry. The fault appears to break into two or perhaps three closely spaced parallel fault segments near the intersection with ridges $\mathrm{A}$ and $\mathrm{B}$ (Fig. 1c). A smaller sub-plateau has also formed near the western margin of the main plateau. This unit is bounded to the north by the main fault and to the south and east by similar normal faults (Fig. 1c), with vertical offsets of $\sim 300 \mathrm{~m}$.

The apparent width of the fault to the $\mathrm{E}$ of ridge $\mathrm{B}$ is $3 \pm 1$ pixels $(110-220 \mathrm{~m})$. The vertical offset is $300 \mathrm{~m}$, giving rise to a fault dip of $54-70^{\circ}$. This angle is higher than the apparent angle from across-track profiles (see Fig. 5), owing to the smoothing which occurs during the stereo processing. The lateral offset seen for ridge B is the opposite of the parallax effect expected for simple down-dip motion, and suggests a lateral component of motion of at most a few hundred meters. The lateral offset of ridges $\mathrm{A}$ and $\mathrm{C}$ is consistent with down-dip motion, but that for A is complicated by the potential offset across a smaller ESE-trending fault to the $\mathrm{N}$ of the main fault.

Fig. 2 shows a topographic map of the area surrounding Manannan crater (diameter $22 \mathrm{~km}$, center $3.2^{\circ} \mathrm{N}, 240.1^{\circ} \mathrm{W}$ ). The topography was derived from stereo (Schenk, 2002) and has a horizontal resolution of $80 \mathrm{~m} / \mathrm{pixel}$ and an estimated vertical precision of $17 \mathrm{~m}$. The flat floor and raised rim of the crater are indicated in Fig. 2; pedestal deposits exterior to the rim are raised by $\sim 100 \mathrm{~m}$ relative to the surrounding terrain (Moore et al., 2001). Just to the west of the crater is a triangular area about $10 \mathrm{~km}$ along each side, bounded by troughs (blue) to the $\mathrm{N}$ and $\mathrm{E}$. The northern trench is both linear and relatively sharp, and trends ENE. The eastern trench extends northwards off the edge of the map. The northern scarp/trench combination is similar to that seen in Fig. $1 b$.

Fig. 3a shows a high resolution Galileo image of the triangular area, and Fig. 3b shows a geological sketch map of the same location. Because of the high solar-illumination, the scene is dominated by albedo variations. Nevertheless, the northern scarp shows up clearly as a highly linear feature. Small lobate features adjoining it to the north may be mass wasting features (cf. Moore et al., 1999). There is a pronounced structural grain in the triangular area, which roughly parallels its northern edge (highlighted in Fig. 3); this grain is not radial to Manannan and is likely to be due to pre-existing ridges rather than ejecta deposits. The eastern margin of the area is defined by a scallopshaped fracture. To the north, this fracture appears to truncate the main northern scarp; to the south, the fracture merges with a number of other fractures to ultimately form a prominent graben (regional images 11E012 and 11E014, not shown). The dark material to the north-east is the continuous ejecta unit of Moore et al. (2001).

A further argument for the linear scarps seen in Figs. 1 and 2 being normal faults comes from a more detailed examination of their topography. Fig. 4a and c plot the topography at the base and the top of the scarps as a function of distance along them. Both plots are noisy, but in the case of Fig. 4a, the data are real and reflect the numerous smaller-scale ridges and double-ridges. In the case of Fig. $4 \mathrm{c}$, the data are noisy due

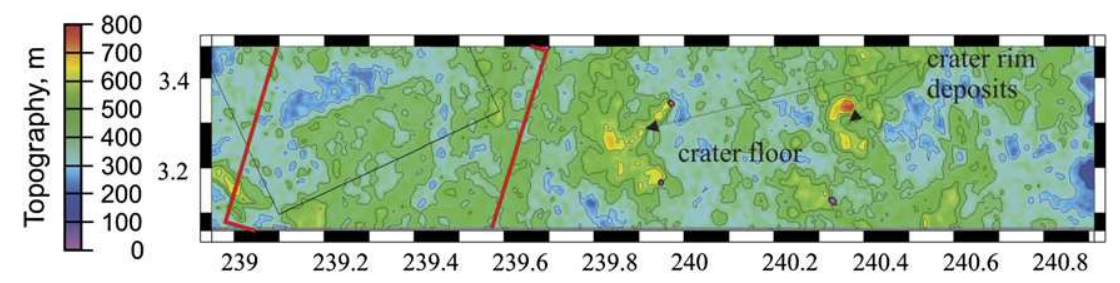

Fig. 2. Stereo topography of Manannan area, Europa, original pixel resolution $80 \mathrm{~m} /$ pixel, vertical error $17 \mathrm{~m}$. Contour interval $100 \mathrm{~m}$. Grid spacing is $0.003^{\circ}$. Red box denotes approximate edges of image shown in Fig. 3. Black box denotes edges of $60 \mathrm{NW}-$ SE profiles used in constructing Figs. 4 and 5. 

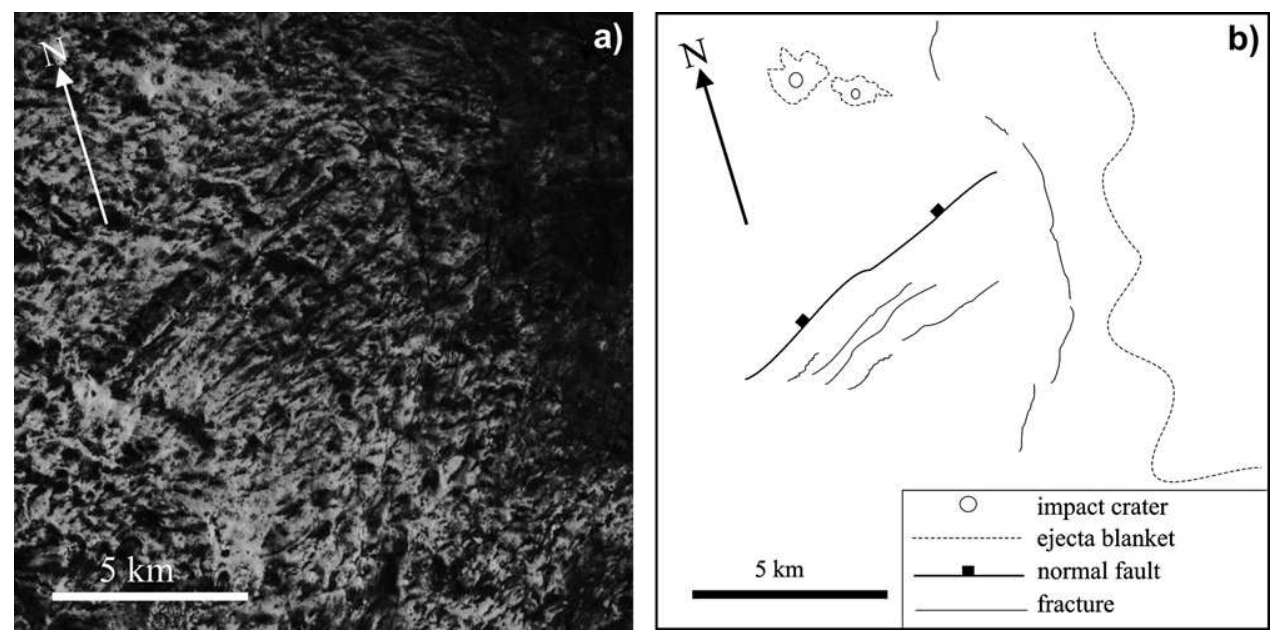

Fig. 3. (a) High-resolution Galileo image from observation sequence 14ESCRATER02 (PDS no. 440948678), resolution $20 \mathrm{~m} /$ pixel. Incidence angle $22^{\circ}$, emission angle $25^{\circ}$, solar azimuth W. (b) Geological sketch map of area, showing main normal fault and minor fractures. The shorter parallel fractures just south of the main fault trace are a part of a set of roughly east-west-trending structures. These are not apparent in the DEM as topographic elements (due to vertical resolution limits), and the high-solar illumination precludes assessing morphology. They may be a set of parallel ridges such as are common across Europa (see Fig. 1).

to a combination of real topography and the spatial resolution limits of the stereo data set. In both cases the topography of the top of the scarp roughly mirrors that at the base, though the amplitude of the former is larger. This kind of pattern is characteristic of normal faults on Earth (see e.g. Grosfils et al., 2003, fig. 7). Fig. 4b and d plots the vertical offset across the scarps, demonstrating that the displacement is maximum towards the center and decays with a relatively steep gradient at either end. Superimposed on Fig. 4b are two displacements profile from terrestrial normal faults (Dawers and Anders,
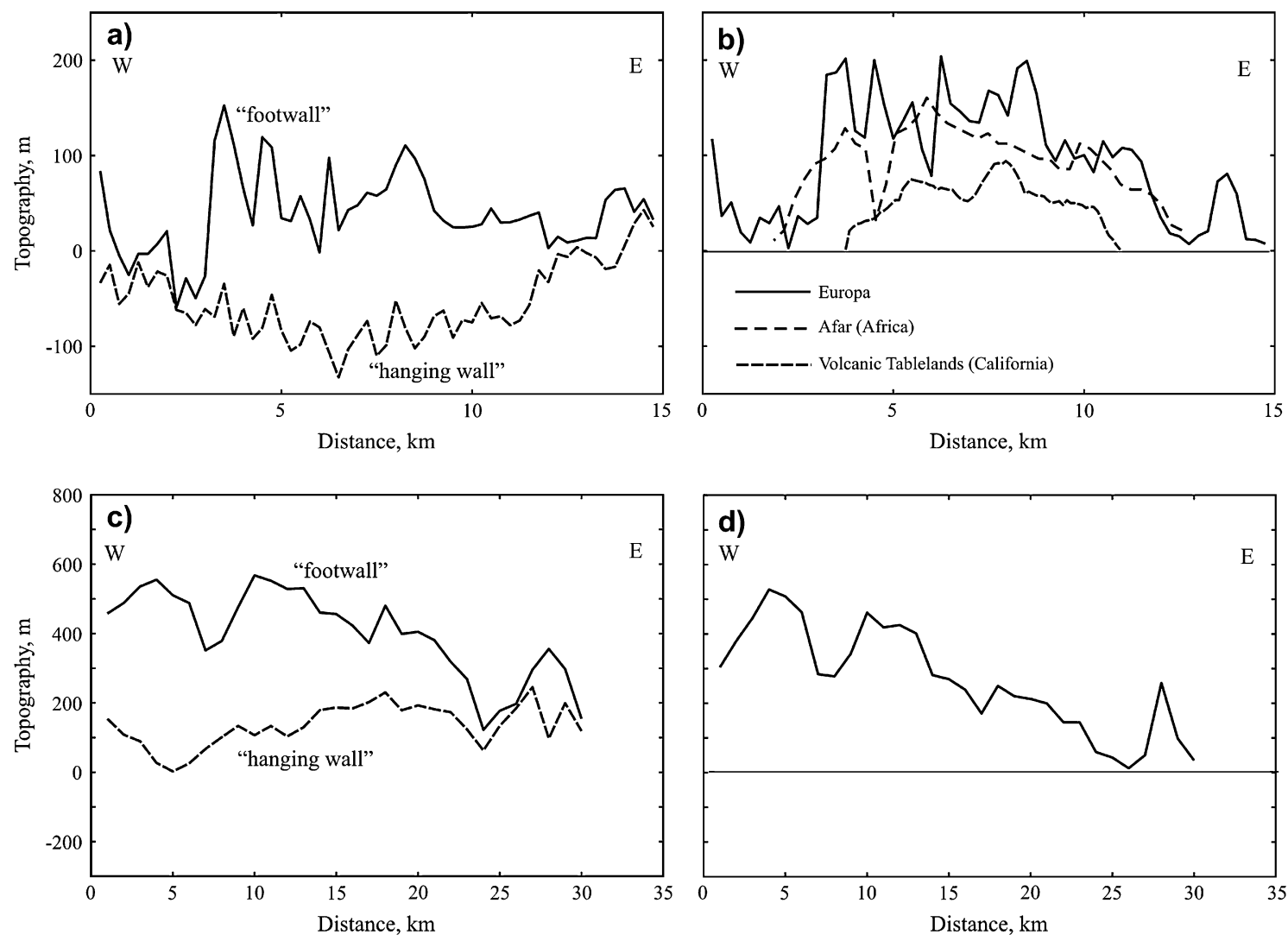

Fig. 4. (a) Maximum and minimum topography as a function of distance along fault scarp, obtained from profiles in Fig. 2. Profile azimuths are $15^{\circ} \mathrm{W}$ of N, separated laterally by $0.25 \mathrm{~km}$. Point spacing $0.25 \mathrm{~km}$, max $/$ min topography determined in window $3-4.5 \mathrm{~km}$ from S end of profile. (b) Throw across fault, calculated from max/min topography in (a). Dashed lines are displacement profiles for two terrestrial normal faults: Afar (Manighetti et al., 2001, fig. 5f) and the Volcanic Tablelands (Dawers and Anders, 1995, fig. 5; , total throw). (c) As for (a), but obtained from profiles in Fig. 1b. Profile azimuths are 20 ${ }^{\circ}$ W of N, separated laterally by $1 \mathrm{~km}$. Point spacing $1 \mathrm{~km}$, max/min topography determined in window 17-22 km from S end of profile. (d) As for (b) but using data from (c). 
1995; Manighetti et al., 2001). The similarities between the terrestrial and Europan profiles are striking. For Fig. $4 \mathrm{~d}$ the situation is slightly more complex: only part of the fault profile is available in stereo, and there is a pronounced drop in displacement at about $7 \mathrm{~km}$. This kink occurs at the point where the through-going ridges $\mathrm{A}$ and $\mathrm{B}$ intersect the fault (see Fig. 1c). Such kinks in displacement are often the result of two faults linking as they grow (e.g. Cartwright et al., 1995; Dawers and Anders, 1995).

\section{Flexural modeling}

On Earth, it has long been recognized that the uplifted footwall of a fault that is sufficiently large will impose a load on the elastic lithosphere and produce a flexural response (e.g. Weissel and Karner, 1989; Kusznir et al., 1991; Brown and Phillips, 1999). Since the elastic thickness of the icy satellites is considerably smaller than that of most terrestrial settings, flexurally-modified fault profiles are likely to occur. The trenches identified to the north of the scarps in Figs. 1 and 2 are strong evidence that such flexural modification is happening.
Fig. 5a and c shows mean across-strike topographic profiles obtained by stacking profiles across the centers of the faults from Figs. 1 and 2. The mean vertical throws on the faults are about 150 and $300 \mathrm{~m}$, respectively. The apparent fault dip angles are $\approx 5^{\circ}$, though these are underestimates due to the smoothing effects of the stereo processing and subsequent profile stacking. In both cases the footwall and hanging wall show topographic curvature, which is characteristic of flexure.

We use the flexural cantilever model of Kusznir et al. (1991) to model the fault-related topography. This model assumes a thin elastic layer, as opposed to an elastic half-space; such a layer is appropriate to a situation in which the fault displacement may be comparable with the likely elastic layer thickness (e.g. Billings and Kattenhorn, 2002; Hurford et al., 2004). In the model, the (planar) fault displacement places an asymmetric load on the surface. Extension is also accommodated by ductile thinning of the base of the ice shell, which will take place over a wider area than the faulting since lower crustal flow is likely to be rapid (Nimmo, 2004a). The distance over which the shell responds to these different loads is primarily governed by its effective elastic thickness $T_{\mathrm{e}}$. Here, we assume that the region in which lower crustal thinning
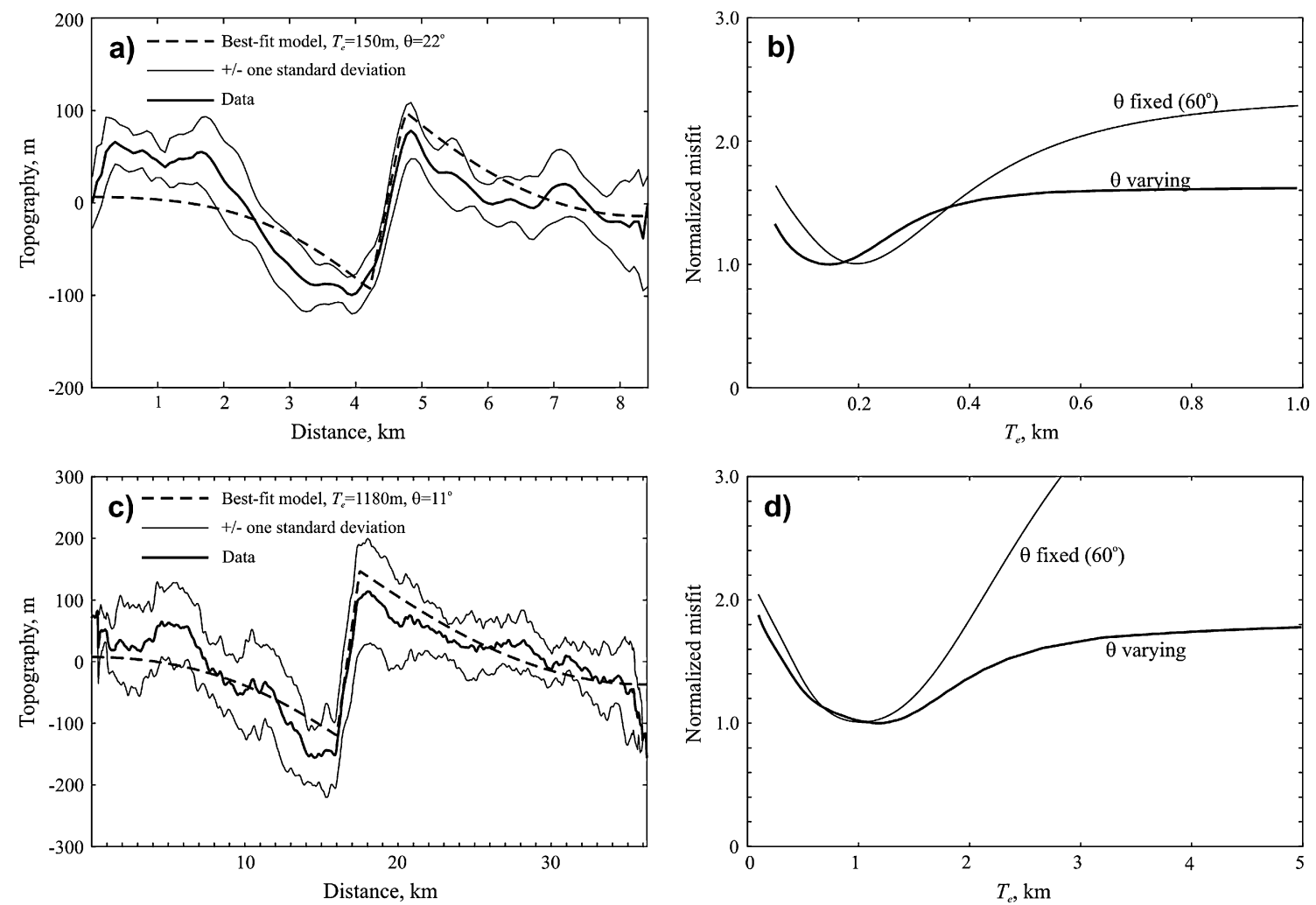

Fig. 5. (a) Topographic profile across Manannan fault, stacked from central profiles (numbers 14-34) shown in Fig. 2. Bold line is data, light lines are \pm one standard deviation. Dashed lines are best fitting model using the approach of Kusznir et al. (1991), with fault dip of $22^{\circ}$ and elastic thickness of $0.15 \mathrm{~km}$. Here, we assume a Young's modulus of $1 \mathrm{GPa}$, an acceleration of $1.3 \mathrm{~m} \mathrm{~s}^{-2}$, ice and ocean densities of 900 and $1000 \mathrm{~kg} \mathrm{~m}^{-3}$, respectively, and a shell thickness of $20 \mathrm{~km}$. The fault extends from 4.35 to $4.9 \mathrm{~km}$. (b) Normalized misfit as a function of elastic thickness, calculated using the method of Nimmo et al. (2003b). Bold line allows dip to vary and gives a minimum misfit of 1.21 standard deviations. Light line keeps dip fixed at $60^{\circ}$ and fault start- and end-points at 4.56 and $4.67 \mathrm{~km}$. Minimum misfit is 1.52 standard deviations, best fit elastic thickness $0.2 \mathrm{~km}$. (c) As for (a), but stacking profiles $1-20$ from Fig. 1. Best-fit elastic thickness is $1.18 \mathrm{~km}$ and fault dip $11^{\circ}$. The fault extends from 16 to $17.5 \mathrm{~km}$. (d) As for (b), but for results shown in (c). Bold line allows dip to vary and gives a minimum misfit of 0.59 standard deviations. Light line keeps dip fixed at $60^{\circ}$ and fault start- and end-points at 16.67 and $16.84 \mathrm{~km}$. Minimum misfit is 0.60 standard deviations, best fit elastic thickness $1.03 \mathrm{~km}$. 
occurs is 30 times wider than the horizontal fault heave, and that the shell thickness is $20 \mathrm{~km}$, but the results are insensitive to these assumptions. Increasing the thinning zone width by two orders of magnitude results in a change in $T_{\mathrm{e}}$ of $<4 \%$; halving the shell thickness changes the results by $<2 \%$.

Fig. 5a and $\mathrm{c}$ shows the best-fit models obtained by simultaneously varying $T_{\mathrm{e}}$ and the fault dip angle $\theta$, while keeping the $x$-coordinates of the top and bottom of the exposed fault surface fixed. The best-fit elastic thicknesses are 0.15 and $1.2 \mathrm{~km}$, respectively (assuming a Young's modulus of $1 \mathrm{GPa}$ ). The best-fit dip angles are 22 and $11^{\circ}$, respectively. As noted in Section 2, these low dip angles are likely a result of the smoothing inherent in the stereo topography. The direct estimate of the dip angle is $54-70^{\circ}$, consistent with expectations for terrestrial normal faults (Jackson and White, 1989) and suggesting that only limited mass-wasting has occurred. We also note that high near-surface fault dips are expected on low gravity bodies, where dilational faulting will extend to greater depths than on Earth (Ferrill et al., 2003).

Fig. $5 b$ and $d$ shows how the misfit between model and observations varies as a function of $T_{\mathrm{e}}$ and demonstrates that the $T_{\mathrm{e}}$ value is well constrained. Results are also shown for the case when $\theta$ is fixed at $60^{\circ}$ and the fault start- and end-points are adjusted to keep the fault throw the same. The best-fit elastic thicknesses are almost unchanged, indicating that $T_{\mathrm{e}}$ is robust to uncertainties in dip angle. Although we have not examined the effects of a listric fault geometry, the $T_{\mathrm{e}}$ results are unlikely to be significantly affected unless the radius of curvature becomes comparable with or smaller than the elastic thickness.

Both profiles, but especially Manannan (Fig. 5a), show flat floors in the hanging wall trough. It is possible that this effect arises due to mass-wasting filling in the low topography, though the image resolution is insufficient to allow direct identification of mass-wasting features. To check that this modification of topography does not significantly influence the results, we carried out additional fits, which excluded the flat floors. For Manannan, the results gave a reduction in $T_{\mathrm{e}}$ from 0 to $50 \%$, depending on the width of the excluded region; similar results were obtained for Fig. 5c.

Topography contrasts such as those seen in Fig. 5a and c result in elastic stresses, which are greatest near the bounding faults. The faults must be able to withstand these stresses, which depend on $T_{\mathrm{e}}$, and the topographic wavelength and amplitude. Thus, the topography and $T_{\mathrm{e}}$ estimates provide a constraint on fault strength (Foster and Nimmo, 1996). Applying the equations of Jackson and White (1989) to Fig. 5a and c, elastic stresses of $0.3-3 \mathrm{MPa}$ are obtained. These stresses are comparable with the frictional stress on a fault $0.3-3 \mathrm{~km}$ deep. Thus, the fault strength required is consistent with other estimates of the Europan brittle-ductile transition depth of a few km (Pappalardo et al., 1999).

\section{Displacement: length ratio}

A particularly important characteristic of normal faults is the displacement:length $(D / L)$ ratio, which may be used to infer the mechanical properties of the material in which faulting occurs (see below). The $D / L$ ratio appears to be independent of fault length (Cowie and Scholz, 1992a) and to have the same range of values on Earth, Venus, Mars and Mercury (Cowie and Scholz, 1992a; Dawers et al., 1993; Clark and Cox, 1996; Schultz, 1997; Watters et al., 2000). No $D / L$ ratios have been published for normal faults on the icy satellites.

The fault shown in Figs. 2 and $4 \mathrm{~b}$ has $L=11 \mathrm{~km}$ and a maximum throw of $200 \mathrm{~m}$. For a fault dipping at $60^{\circ}$ the down-dip displacement is $230 \mathrm{~m}$, giving a $D / L$ ratio of 0.021 . The corresponding ratios for the terrestrial faults shown in Fig. $4 \mathrm{~b}$ are 0.015 and 0.013 . For the fault shown in Figs. 1 and $4 d$, the $D / L$ ratio is harder to interpret because only part of the fault was imaged. The topographic data (Fig. 4d) place a lower bound on the fault length of $25 \mathrm{~km}$, but the low resolution image (Fig. 1a and c) suggests that the fault extends at least an additional $4 \mathrm{~km}$ to the west. For a fault length of $30 \mathrm{~km}$, a maximum throw of $600 \mathrm{~m}$ and a fault dip of $60^{\circ}$, the $D / L$ ratio is 0.023 , very similar to that for Fig. 2. The local horizontal extension associated with these two faults is 115 and $350 \mathrm{~m}$, respectively, assuming a fault dip of $60^{\circ}$. The similarity between the terrestrial and Europan $D / L$ ratios is striking, given that the faulting is occurring in two very different materials.

On Earth, sedimentation or mass-wasting can reduce the apparent $D / L$ ratio (Grosfils et al., 2003), but this is probably a minor effect on Europa. The steep fault-tip gradient on the $\mathrm{E}$ end of the fault in Fig. 4b may be due to interactions with the $\mathrm{N}$-trending fracture system, potentially increasing the $D / L$ ratio (cf. Mansfield and Cartwright, 2001). However, the W end of the fault also shows a similar fault-tip gradient and appears to be relatively isolated. As noted above, the kink in the displacement profile of Fig. 4d is likely to be due to fault linkage.

A simple model developed by Cowie and Scholz (1992b) allows the $D / L$ ratio to be related to the mechanical properties of, and stresses on, a fault. These authors take into account inelastic deformation near the fault tip, and show that the $D / L$ ratio $\gamma$ is given by

$$
\begin{aligned}
& \gamma=\frac{(1-\nu)\left(\sigma_{0}-\sigma_{\mathrm{f}}\right)}{2 \pi \mu}\left[\cos \theta_{2} \ln \frac{\left(\sin \theta_{2}+1\right)^{2}}{\left(\sin \theta_{2}-1\right)^{2}}\right] \\
& \theta_{2} \approx \cos ^{-1}\left(1-\frac{\pi^{2}\left(\sigma_{\mathrm{a}}-\sigma_{\mathrm{f}}\right)^{2}}{8\left(\sigma_{0}-\sigma_{\mathrm{f}}\right)^{2}}\right)
\end{aligned}
$$

where $\nu$ is Poisson's ratio, $\sigma_{0}$ is the shear strength of intact rock, $\sigma_{\mathrm{f}}$ is the residual frictional stress on the fault, $\mu$ is the shear modulus, $\sigma_{\mathrm{a}}$ is the remote shear stress and $\theta_{2}$ is a parameter that depends on the size of the inelastic zone at the fault tip (see below). While this model undoubtedly neglects important effects such as strength inhomogeneities (Cowie and Shipton, 1998) and three-dimensional effects (Schultz and Fossen, 2002), it provides a first-order description of likely processes. Terrestrial faults show a wide variety of scatter in $\gamma$ (e.g. Dawers et al., 1993; Cartwright et al., 1995), so that some caution needs to be used when interpreting the results for individual faults. Nonetheless, to demonstrate the utility of this approach, we here apply Eq. (1) to our examples. 
In their original work, Cowie and Scholz (1992b) assumed that $\theta_{2}$ was a constant, determined by field studies of the length $s$ of the inelastic deformation zone $\left(\theta_{2}=\right.$ $\left.\cos ^{-1}[1-2(s / L)]\right)$. Fig. $4 \mathrm{~b}$ suggests that the length of the fault-tip zone for the Europan case is likely to be similar to terrestrial values, so we will also assume $\theta_{2}$ is constant. Note that this is equivalent to assuming a constant ratio between $\left(\sigma_{\mathrm{a}}-\sigma_{\mathrm{f}}\right)$ and $\left(\sigma_{0}-\sigma_{\mathrm{f}}\right)$.

In order to calculate the theoretical value of $\gamma$ from Eq. (1), we need the intact shear strength $\sigma_{0}$ and the residual frictional stress $\sigma_{\mathrm{f}}$. However, since $\theta_{2}$ is assumed known, Eq. (2) shows that $\sigma_{0}$ may be derived from $\sigma_{\mathrm{f}}$ and the driving stress, $\sigma_{\mathrm{a}}$. Here, we will fix $\sigma_{\mathrm{f}}$, a relatively well-known quantity, and calculate $\gamma$ as a function of $\sigma_{\mathrm{a}}$, the quantity of most geophysical interest.

The residual frictional stress on the fault, $\sigma_{\mathrm{f}}$, depends on the overburden pressure and the friction coefficient. The maximum overburden pressure is set by the depth to the brittle-ductile transition, probably a few kilometers depth (Pappalardo et al., 1999). The friction coefficient of ice at the low temperatures appropriate to the brittle region is similar to that for rock (Kennedy et al., 2000), although friction is reduced at higher temperatures or strain rates (Rist, 1997). Based on these results and the values obtained in Section 3, we will assume $\sigma_{\mathrm{f}}=1 \mathrm{MPa}$, a conservatively low value. The shear modulus of intact ice is $4 \mathrm{GPa}$ (Gammon et al., 1983), but fractures or pores may reduce this value. Diurnal tidal stresses on Europa are $\sim 0.1 \mathrm{MPa}$, while stresses due to non-synchronous rotation or polar wander (Leith and McKinnon, 1996; Greenberg et al., 2003) may be up to a few MPa, and stresses due to ice-shell freezing may exceed $10 \mathrm{MPa}$ (Nimmo 2004b).

Fig. 6 plots how $\gamma$ varies as a function of the remote applied shear stress $\sigma_{\mathrm{a}}$ when $\theta_{2}$ is constant. It shows that for an intact ice shear modulus of $4 \mathrm{GPa}$, the predicted value of $\gamma$ is an order of magnitude smaller than that observed for stresses $\leq 10 \mathrm{MPa}$. To obtain the measured value of $\gamma$ requires a significant reduction in the shear modulus $\mu$, depending on the remote shear stress applied. As we discuss below, the likely porous and/or fractured nature of the near-surface is unlikely

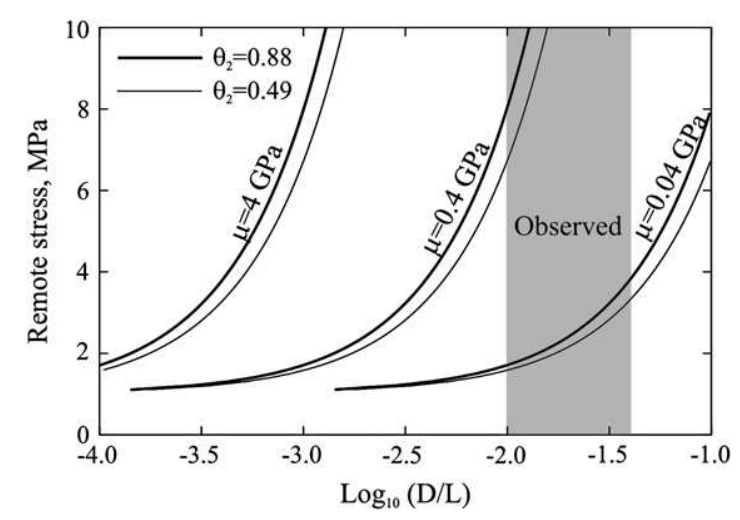

Fig. 6. Predicted $D / L$ ratio ( $\gamma$ in Eq. (1)) as a function of remote stress. $\theta_{2}$ (in radians) is assumed constant; the equivalent values of $s / L$ are 0.18 and 0.06 (see text). Fractured fault strength $\sigma_{\mathrm{f}}$ is $1 \mathrm{MPa}$, Poisson's ratio $\nu 0.25, \mu$ is the shear modulus. Shaded box denotes the observed $D / L$ ratio $(0.02$ with a factor of 2 error). to result in a reduction of shear modulus exceeding one order of magnitude. Fig. 6 shows that an order of magnitude reduction in $\mu$ implies remote shear stresses of at least 6-8 MPa. If $\mu$ is reduced by two orders of magnitude, shear stresses of about $2 \mathrm{MPa}$ are sufficient. These stresses increase if the value of $\sigma_{\mathrm{f}}$ is increased; reasonable variations in $\theta_{2}$ have little effect on the final results. For driving stresses of $6-8 \mathrm{MPa}$, the intact strength of ice $\sigma_{0}$ is $10-22 \mathrm{MPa}$ for the values of $\theta_{2}$ assumed (Eq. (2)). This range is spanned by experimentally determined shear strengths, which typically vary with both pressure and strain rate (Rist, 1997).

The implications of the results shown in Fig. 6 are discussed below; here, we will simply note that a reduction in $\mu$ of one order of magnitude is possible for highly porous ice, and that the corresponding stresses required $(\geq 6-8$ $\mathrm{MPa})$ greatly exceed the diurnal tidal stresses.

\section{Discussion}

The principal results of this paper may be summarized as follows. Based on images and stereo topography, we have identified two examples of potential normal faulting on $\mathrm{Eu}-$ ropa (Figs. 1-3). The measured $D / L$ ratios are similar to those of terrestrial faults (Fig. 4). A simple flexural model of the across-strike topography (Fig. 5) suggests effective elastic thicknesses of 0.15 and $1.2 \mathrm{~km}$ for the two faults examined (these values may be reduced by up to $50 \%$ if mass-wasting is important). We used our observations of the $D / L$ ratio and a modified linear elastic fracture mechanics model to infer that the effective shear modulus of the ice is significantly lower than that of unfractured laboratory samples. A reduction in shear modulus by one order of magnitude still requires driving stresses which are two orders of magnitude greater than diurnal tidal stresses (Fig. 6).

In chaos terrain on Europa, tilted blocks similar to those observed in Fig. 3 have been interpreted as iceberg-like features originally floating in water (e.g. Williams and Greeley, 1998; Greenberg et al., 1999), rather than the result of normal faulting. If such models are correct, the subsequent re-freezing of the water would not lead to the kind of trench observed in Figs. 1 and 2. Such a trench, however, is entirely characteristic of normal faulting, where footwall uplift is accompanied by downdropping of the hanging wall.

An alternative model for chaos formation appeals to diapirism (e.g. Head and Pappalardo, 1999), which may also be responsible for the elevated areas observed in Figs. 1 and 2 (cf. Schenk and Pappalardo, 2004). On Earth, salt diapirism is often the cause of uplift and faulting in overlying layers (e.g. Davison et al., 2000). Therefore, irrespective of how the elevated areas formed, we conclude that the observed scarps are most likely normal faults.

The $T_{\mathrm{e}}$ values of 0.15 and $1.2 \mathrm{~km}$ obtained in Section 3 assumed a conservatively low value for the Young's modulus of $1 \mathrm{GPa}$, based on the likely reduction in shear modulus (Section 4). Using a lab-derived, but probably less appropriate (Nimmo, $2004 \mathrm{c}$ ), value of $9 \mathrm{GPa}$ results in $T_{\mathrm{e}}$ values of 0.07 and $0.6 \mathrm{~km}$, respectively. In either case, the values obtained are smaller 
than those found by some authors (Figueredo et al., 2002; Nimmo et al., 2003b), but are similar to estimates based on double-ridge (Tufts et al., 1997; Billings and Kattenhorn, 2002; Hurford et al., 2004) and chaos (Williams and Greeley, 1998 ) regions. The variability in $T_{\mathrm{e}}$ estimates derived here, and in other studies, may be due to either spatial or temporal variations in shell properties.

The $D / L$ ratios obtained here $(\approx 0.02)$ are comparable with values obtained for normal faults on silicate planets. Watters et al. (2000) plot $D / L$ ratios for faults on the Earth, Mars and Mercury and find typical values of $0.01-0.1$.

Because of the simplified nature of the model applied (Eqs. (1) and (2)), quantitative conclusions regarding the modeling of $D / L$ ratios must be regarded as preliminary. Nonetheless, the most likely explanation for the reduced shear modulus required by Fig. 6 is that the near-surface ice on Europa is highly porous, owing to a combination of impacts and fractures (Nimmo et al., 2003a; Eluszkiewicz, 2004). Depending on the shell thickness, such porosity can persist to a depth of several kilometers (Nimmo et al., 2003a), similar to the likely brittle-ductile transition depth. The seismic and radar properties of the near-surface material are likely to be significantly affected by the presence of high porosity (Eluszkiewicz, 2004; Lee et al., in press).

In terrestrial sea ice, elastic moduli are reduced by a factor of $50-80 \%$ for a brine volume of $10 \%$ (Weeks and Cox, 1984, figs. 25 and 26). The tensile strength of sea ice is reduced by no more than an order of magnitude for porosities exceeding $10 \%$ (Lee et al., in press). Hessinger et al. (1996, fig. 4) show that porosity in excess of 50\% is required to reduce the elastic modulus by an order of magnitude for a range of materials. These results suggest that the reduction in $\mu$ due to porosity is unlikely to exceed an order of magnitude, and thus that driving stresses $\geq 6-8 \mathrm{MPa}$ are required (see Fig. 6). These inferred stresses are roughly two orders of magnitude higher than the present-day diurnal tidal stresses, and are comparable with the stresses obtained in an earlier flexural study of Europa (Nimmo et al., 2003b). Stresses of a few megapascal can be generated by non-synchronous rotation (e.g. Greenberg et al., 2003), for which there is some observational evidence (e.g. Figueredo and Greeley, 2000; Kattenhorn, 2002). An alternative source of comparable stress is polar wander (Leith and McKinnon, 1996). Perhaps more plausibly, thickening of an ice shell can generate stresses of $10 \mathrm{MPa}$ or more, which are purely extensional (Nimmo, 2004b), thus helping to explain the predominance of extensional features observed.

A reduction in near-surface shear modulus by an order of magnitude will reduce shear velocities by a factor of $\approx 3$ and affect seismic wave propagation (e.g. Lee et al., 2003). The resulting crack propagation velocities are still much higher than those of $\sim 1 \mathrm{~m} \mathrm{~s}^{-1}$ inferred on the basis of a cycloid formation model (Hoppa et al., 1999), and suggest that the interrupted crack propagation mechanism of Lee et al. (in press) may be correct.

Although we have so far identified only two normal faults on Europa, it is likely that many other similar faults exist. Identification of such faults will affect predictions of seismicity, important for future mission design (Kovach and Chyba, 2001; Lee et al., 2003). Terrestrial faults typically break when the strain exceeds $\approx 0.005 \%$ (e.g. Scholz, 2002). If the same critical strain applies to the larger $(L=30 \mathrm{~km})$ Europan fault, the fault slip during an individual event will be $\approx 0.5 \mathrm{~m}$. Assuming a down-dip distance of $4 \mathrm{~km}$ and a shear modulus of $0.4 \mathrm{GPa}$, the maximum moment release (if the entire fault moves) is $10^{17} \mathrm{~N} \mathrm{~m}$. This is equivalent to a seismic magnitude $M_{\mathrm{s}}=5.3$ (Scholz, 2002) and is considerably larger than the moments predicted by Lee et al. (2003). To generate the observed maximum fault offset of $600 \mathrm{~m}$ will take roughly 400 events. Since the surface age of Europa is $\sim 60 \mathrm{Myr}$ (Zahnle et al., 2003), the minimum strain rate is on the order of $10^{-17} \mathrm{~s}^{-1}$. In practice, deformation is likely to occur during shorter periods of higher strain rate, as suggested by models of rifting on Europa (Nimmo, 2004d).

In summary, the identification of normal faults on Europa allows the application of a range of terrestrial techniques to characterize the mechanical properties of the near-surface material. The fault characteristics are consistent with a near-surface ice layer, which is significantly weaker than that of unfractured ice, probably as a result of high porosity. This high-porosity layer is likely to have radar and seismic properties different to unfractured ice, and is also likely to influence the development of shallow fractures and the modification of short-wavelength topography. The stresses required to generate the observed faults greatly exceed diurnal tidal values and are more consistent with stresses arising from non-synchronous rotation or progressive thickening of the ice shell.

\section{Acknowledgements}

Support provided by NASA grant NNG04GE89G and OPR-0045-0122; we are grateful for careful reviews by Geoff Collins and Simon Kattenhorn.

\section{References}

Billings, S.E., Kattenhorn, S.A., 2002. Determination of ice crust thickness from flanking cracks along ridges on Europa. Lunar and Planetary Science Conference XXXIII. abstract no. 1813.

Brown, C.D., Phillips, R.J., 1999. Flexural rift flank uplift at the Rio Grande Rift, New Mexico. Tectonics 18, 1275-1291.

Cartwright, J.A., Trudgill, B.D., Mansfield, C.S., 1995. Fault growth by segment linkage - an explanation for scatter in maximum displacement and trace length data from the Canyonlands graben of S.E. Utah. Journal of Structural Geology 17, 1319-1326.

Clark, R.M., Cox, S.J.D., 1996. A modern regression approach to determining fault displacement-length scaling relationships. Journal of Structural Geology 18, 147-152.

Collins, G.C., Head, J.W., Pappalardo, R.T., 1998. The role of extensional instability in creating Ganymede grooved terrain: insights from Galileo highresolution stereo imaging. Geophysical Research Letters 25, 233-236.

Cowie, P.A., Scholz, C.H., 1992. Displacement-length scaling relationship for faults: data synthesis and discussion. Journal of Structural Geology 14, 1149-1156.

Cowie, P.A., Scholz, C.H., 1992. Physical explanation for the displacementlength relationship of faults using a post-yield fracture mechanics model. Journal of Structural Geology 14, 1133-1148. 
Cowie, P.A., Shipton, Z.K., 1998. Fault tip displacement gradients and process zone dimensions. Journal of Structural Geology 20, 983-997.

Davison, I., Alsop, G.I., Evans, N.G., Sararicz, M., 2000. Overburden deformation patterns and mechanisms of salt diapir penetration in the Central Graben, North Sea. Marine Petroleum Geology 17, 601-618.

Dawers, N.H., Anders, M.H., 1995. Displacement-length scaling and fault linkage. Journal of Structural Geology 17, 607-614.

Dawers, N.H., Anders, M.H., Scholz, C.H., 1993. Growth of normal fault: displacement-length scaling. Geology 21, 1107-1110.

Eluszkiewicz, J., 2004. Dim prospects for radar detection of Europa's ocean. Icarus 170, 234-236.

Ferrill, D.A., Morris, A.P., Waiting, D.J., Franklin, N.M., Sims, D.W., 2003. Influence of gravity on the geometry of Martian normal faults. Lunar and Planetary Science Conference XXXIV. abstract no. 2050.

Figueredo, P.H., Greeley, R., 2000. Geologic mapping of the northern leading hemisphere of Europa from Galileo solid-state imaging data. Journal of Geophysical Research 105, 22629-22646.

Figueredo, P.H., Greeley, R., 2004. Resurfacing history of Europa from poleto-pole geological mapping. Icarus 167, 287-312.

Figueredo, P., Chuang, F.C., Rathbun, J., Kirk, R.L., Greeley, R., 2002. Geology and origin of Europa's Mitten feature (Murias Chaos). Journal of Geophysical Research 107, 5026.

Foster, A., Nimmo, F., 1996. Comparisons between the rift systems of East Africa, Earth and Beta Regio, Venus, Earth. Planetary Science Letters 143, 183-195.

Gammon, P.H., Kiefte, H., Clouter, M.J., Denner, W.W., 1983. Elastic constants of artificial and natural ice samples by Brillouin spectroscopy. Journal of Glaciology 29, 433-460.

Giese, B., Oberst, J., Roatsch, T., Neukum, G., Head, J.W., Pappalardo, R.T., 1998. The local topography of Uruk Sulcus and Galileo Regio obtained from stereo images. Icarus 135, 303-316.

Greenberg, R., Geissler, P., Hoppa, G., Tufts, B.R., Durda, D.D., Pappalardo, R., Head, J.W., Greeley, R., Sullivan, R., Carr, M.H., 1998. Tectonic processes on Europa: tidal stresses, mechanical response and visible features. Icarus $135,64-78$.

Greenberg, R., Hoppa, G.V., Tufts, B.R., Geissler, P., Riley, J., 1999. Chaos on Europa. Icarus 141, 263-286.

Greenberg, R., Hoppa, G.V., Bart, G., Hurford, T., 2003. Tidal stress patterns on Europa's crust. Celestial Mechanics and Dynamic Astronomy 87, 171-188.

Grosfils, E.B., Schultz, R.A., Kroeger, G., 2003. Geophysical exploration within northern Devils Lane graben, Canyonlands National Park, Utah: implications for sediment thickness and tectonic evolution. Journal of Structural Geology 25, 455-467.

Head, J.W., Pappalardo, R.T., 1999. Brine mobilization during lithospheric heating on Europa: implications for formation of chaos terrain, lenticula texture, and color variations. Journal of Geophysical Research 104, 27143-27155.

Head, J.W., Pappalardo, R.T., Sullivan, R., 1999. Europa: morphological characteristics of ridges and triple bands from Galileo data (E4 and E6) and assessment of a linear diapirism model. Journal of Geophysical Research 104, 24223-24236.

Hessinger, J., White, B.E., Pohl, R.O., 1996. Elastic properties of amorphous and crystalline ice films. Planetary and Space Science 44, 937-944.

Hoppa, G.V., Tufts, B.R., Greenberg, R., Geissler, P.E., 1999. Formation of cycloidal features on Europa. Science 285, 1899-1902.

Hoppa, G., Greenberg, R., Tufts, B.R., Geissler, P., Phillips, C., Milazzo, M., 2000. Distribution of strike-slip faults on Europa. Journal of Geophysical Research 105, 22617-22627.

Hurford, T.A., Preblich, B., Beyer, R.A., Greenberg, R., 2004. Flexure of Europa's lithosphere due to ridge-loading. Lunar and Planetary Science Conference XXXV. abs. no. 1831.

Jackson, J.A., White, N.J., 1989. Normal faulting in the upper continental crust-observations from regions of active extension. Journal of Structural Geolog. 11, 15-36.

Kattenhorn, S.A., 2002. Nonsynchronous rotation evidence and fracture history in the Bright Plains region, Europa. Icarus 157, 490-506.

Kennedy, F.E., Schulson, E.M., Jones, D.E., 2000. The friction of ice on ice at low sliding velocities. Philosophical Magazine A 80, 1093-1110.
Kovach, R.L., Chyba, C.F., 2001. Seismic detectability of a subsurface ocean on Europa. Icarus 150, 279-287.

Kusznir, N.J., Marsden, G., Egan, S.S., 1991. A flexural-cantilever simpleshear/pure-shear model of continental lithosphere extension: applications to the Jeanne d'Arc Basin, Grand Banks and Viking graben, North Sea. In: Roberts, A.M., Yielding, G., Freeman, B. (Eds.), The Geometry of Normal Faults. Geological Society, Special Publication, 56, pp. 41-60.

Lee, S.W., Zanolin, M., Thode, A.M., Pappalardo, R.T., Makris, N.C., 2003. Probing Europa's interior with natural sound sources. Icarus 165, 144-167.

Lee, S.W., Pappalardo, R.T., Makris, N.C., in press. Mechanics of tidally driven fractures in Europa's ice shell. Icarus, in press.

Leith, A.C., McKinnon, W.B., 1996. Is there evidence for polar wander on Europa? Icarus 120, 387-398.

Manighetti, I., King, G.C.P., Gaudemer, Y., Scholz, C.H., Doubre, C., 2001. Slip accumulation and lateral propagation of active normal faults in Afar. Journal of Geophysical Research 106, 13667-13696.

Mansfield, C., Cartwright, J., 2001. Fault growth by linkage: observations and implications from analogue models. Journal of Structural Geology 23, 745-763.

Michalski, J.R., Greeley, R., 2002. En echelon ridge and trough structures on Europa. Geophysical Research Letters 29, 1498.

Moore, J.M., Asphaug, E., Morrison, D., Spencer, J.R., Chapman, C.R., Bierhaus, B., Sullivan, R.J., Chuang, F.C., Klemaszewski, J.E., Greeley, R., Bender, K.C., Geissler, P.E., Helfenstein, P., Pilcher, C.B., 1999. Mass movement and landform degradation on the icy Galilean satellites: results of the Galileo nominal mission. Icarus 140, 294-312.

Moore, J.M., Asphaug, E., Morrison, D., Sullivan, R.J., Chapman, C.R., Greeley, R., Klemaszewski, J.E., Kadel, S., Chuang, F., Moreau, J., Williams, K.K., Geissler, P.E., McEwen, A.S., Turtle, E.A., Phillips, C.B., Tufts, B.R., Head, J.W., Pappalardo, R.T., Collins, G.C., Neukum, G., Wagner, R., Galileo SSI Team, 2001. Impact features on Europa: results of the Galileo Europa mission (GEM). Icarus 151, 93-111.

Nimmo, F., 2004. Non-Newtonian topographic relaxation on Europa. Icarus 168, 205-208.

Nimmo, F., 2004. Stresses generated in cooling viscoelastic ice shells: application to Europa. Journal of Geophysical Research 109, E12001.

Nimmo, F., 2004. What is the Young's modulus of ice? Europa's Icy Shell Meeting. LPI Houston. abstract no. 7005.

Nimmo, F., 2004. Dynamics of rifting and modes of extension on icy satellites. Journal of Geophysical Research 109, E01003.

Nimmo, F., Pappalardo, R.T., Giese, B., 2002. Elastic thickness and heat flux estimates on Ganymede. Geophysical Research Letters 29, 1158.

Nimmo, F., Pappalardo, R.T., Giese, B., 2003. On the origins of band topography, Europa. Icarus 166, 21-32.

Nimmo, F., Giese, B., Pappalardo, R.T., 2003. Estimates of Europa's ice shell thickness from elastically-supported topography. Geophysical Research Letters 30 (5), 1233.

Pappalardo, R.T., Collins, G.C., 2005. Strained craters on Ganymede. Journal of Structural Geology 27, 827-838.

Pappalardo, R.T., Belton, M.J.S., Breneman, H.H., Carr, M.H., Chapman, C.R., Collins, G.C., Denk, T., Fagents, S., Geissler, P.E., Giese, B., Greeley, R., Greenberg, R., Head, J.W., Helfenstein, P., Hoppa, G., Kadel, S.D., Klaasen, K.P., Klemaszewski, J.E., Magee, K., McEwen, A.S., Moore, J.M., Moore, W.B., Neukum, G., Phillips, C.B., Prockter, L.M., Schubert, G., Senske, D.A., Sullivan, R.J., Tufts, B.R., Turtle, E.P., Wagner, R., K.K. Williams, K.K., 1999. Does Europa have a subsurface ocean? Evaluation of the geological evidence. Journal of Geophysical Research 104, 24015-24055.

Patterson, G.W., Head, J.W., Pappalardo, R.T., 2004. Convergent boundaries on Europa: a numerical approach to Euler pole analysis and its implications for plate reconstruction. Lunar and Planetary Science Conference XXXV. abstract no. 1590.

Prockter, L.M., Head, J.W., Senske, D., Pappalardo, R.T., Neukum, G., Wagner, R., Wolf, U., Oberst, J., Giese, B., Moore, J.M., Chapman, C.R., Helfenstein, P., Greeley, R., Breneman, H.H., Belton, M.J.S., 1998. Dark terrain on Ganymede: geological mapping and interpretation of Galileo Regio at high resolution. Icarus 135, 317-344. 
Prockter, L.M., Head III, J.W., Pappalardo, R.T., Sullivan, R.J., Clifton, A.E., Giese, B., Wagner, R., Neukum, G., 2002. Morphology of Europan bands at high resolution: a mid-ocean ridge-type rift mechanism. Journal of Geophysical Research 107, 5028.

Rist, M.A., 1997. High-stress ice fracture and friction. Journal of Physical Chemistry B 101, 6263-6266.

Sarid, A.R., Greenberg, R., Hoppa, G.V., Hurford, T.A., Tufts, B.R., Geissler, P., 2002. Polar wander and surface convergence of Europa's ice shell: evidence from a survey of strike-slip displacement. Icarus 158, 24-41.

Schenk, P.M., 2002. Thickness constraints on the icy shells of the Galilean satellites from a comparison of crater shapes. Nature 417, 419-421.

Schenk, P.M., Moore, J.M., 1995. Volcanic constructs on Ganymede and Enceladus-Topographic evidence from stereo images and photoclinometry. Journal of Geophysical Research 100, 19009-19022.

Schenk, P.M., Pappalardo, R.T., 2004. Topographic variations in chaos on Europa: implications for diapiric formation. Geophysical Research Letters 31, L16703.

Schenk, P.M., Wilson, R.R., Davies, A.G., 2004. Shield volcano topography and the rheology of lava flows on Io. Icarus 169, 98-110.

Scholz, C.H., 2002. The Mechanics of Earthquakes and Faulting. Second ed. Cambridge University Press, Cambridge.

Schulson, E.M., 2002. On the origin of a wedge crack within the icy crust of Europa. Journal of Geophysical Research 107, 5107.
Schultz, R.A., 1997. Displacement-length scaling for terrestrial and Martian faults: implications for Valles Marineris and shallow planetary grabens. Journal of Geophysical Research 102, 12009-12015.

Schultz, R.A., Fossen, H., 2002. Displacement-length scaling in three dimensions: the importance of aspect ratio and application to deformation bands. Journal of Structural Geology 24, 1389-1411.

Spaun, N.A., Pappalardo, R.T., Head, J.W., 2003. Evidence for shear failure in forming near-equatorial lineae on Europa. Journal of Geophysical Research 108, 5060.

Tufts, B.R., Greenberg, R., Geissler, P., Hoppa, G., Pappalardo, R., Sullivan, R., 1997. Crustal displacement features on Europa. Geological Society America Abstract Programs 29, A-312.

Watters, T.R., Schultz, R.A., Robinson, M.S., 2000. Displacement-length relations of thrust faults associated with lobate scarps on Mercury and Mars: comparison with terrestrial faults. Geophysical Research Letters 27, 3659-3662.

Weeks, W.F., Cox, G.F.N., 1984. The mechanical properties of sea ice: a status report. Ocean Science Engineering 9, 135-198.

Weissel, J.K., Karner, G.D., 1989. Flexural uplift of rift flanks due to mechanical unloading of the lithosphere during extension. Journal of Geophysical Research 94, 13919-13950.

Williams, K.K., Greeley, R., 1998. Estimates of ice thickness in the Conamara Chaos region of Europa. Geophysical Research Letters 25, 4273-4276.

Zahnle, K., Schenk, P., Levison, H., Dones, L., 2003. Cratering rates in the outer solar system. Icarus 163, 263-289. 